\title{
Pharmacy Practice and the Health Care System in Saudi Arabia
}

\author{
Ahmed Al-jedai, Shrouq Qaisi, and Ahmed Al-meman
}

\section{THE KINGDOM OF SAUDI ARABIA: AN INTRODUCTION}

$\mathrm{T}$

The Kingdom of Saudi Arabia is one of the Gulf Arab states in the Middle East, with an area spanning 2.5 million $\mathrm{km}^{2} .{ }^{1}$ It is considered a wealthy country, with a relatively high human development index (rank of 34 in 2014). ${ }^{2,3}$ In the World Health Organization's World Health Report 2000, its health care system was ranked 26th out of 190 in the world. ${ }^{4}$ The population is 30.7 million, of whom 20.7 million are Saudi citizens and the rest are expatriates. The sex ratio (male to female) is about even, at $1: 1 .^{5}$

Unlike the situation in developed countries, the Saudi population is overwhelmingly young, with a median age of 28 years and only $3 \%$ of the population aged 65 years or older (2013 data). ${ }^{6}$ The average life expectancy is 74 and 78 years for men and women, respectively; this represents a 3 -year increase over the span of 2000 to $2012 . .^{7}$ The population growth rate, at $3.2 \%$, is reported to be one of the highest in the world. ${ }^{8}$ Furthermore, there has been a reduction in neonatal and infant mortality rates, which are reported at 10.7 and 15.5 per 1000 live births, respectively. ${ }^{1,2}$ Improvements in health care and outreach programs and the institution of free, national, mandatory child immunization programs are a few of the factors that have contributed to the decreases in neonatal and infant mortality rates and the increase in life expectancy. ${ }^{9}$ According to the Ministry of Health $(\mathrm{MOH})$, national immunization rates have increased from $95 \%$ to $98 \%$, and the prevalence of measles decreased by more than two-thirds during the period from 2006 to 2013 (see Table 3-1 in the 2013 health statistics yearbook ${ }^{6}$ ).

The per capita total expenditure on health care has increased substantially, from US\$200 in 1995 to US\$1004 in 2015, which makes it the sixth highest in the Middle East and African region. ${ }^{10}$ Total health care expenditure is roughly US $\$ 31.7$ billion and is predicted to increase to US $\$ 44$ billion by 2019 (Figure 1). ${ }^{10}$ Similar to the situation in some Western countries, cardiovascular disease and diabetes mellitus cause a huge health burden. According to the World Health Organization, in 2012 the top 10 causes of death were ischemic

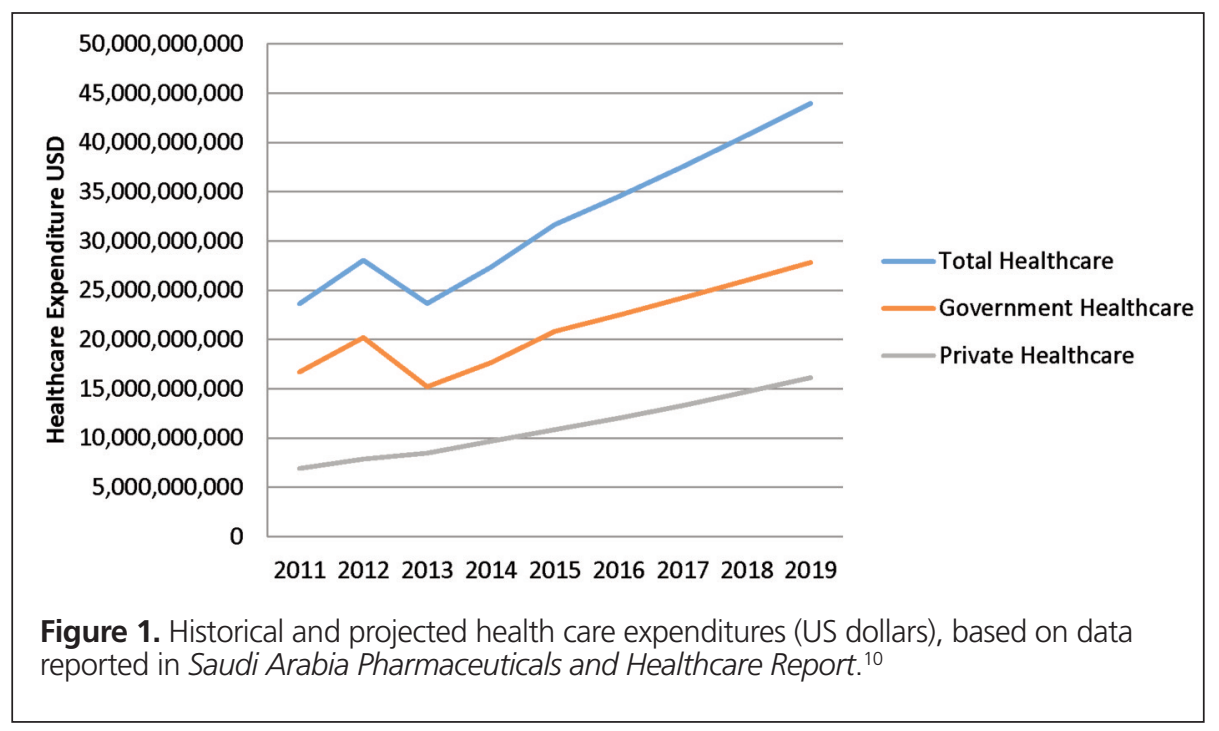


heart disease $(21.7 \%)$, stroke $(16 \%)$, lower respiratory tract infections $(6.3 \%)$, road traffic accidents $(5.8 \%)$, diabetes (4.6\%), kidney disease (4.6\%), hypertension (2.8\%), chronic obstructive pulmonary disease (1.7\%), congenital anomalies (1.7\%), and preterm birth complications (1.7\%). ${ }^{7}$ Moreover, the noncommunicable disease burden is predicted to further increase because of the inactive lifestyle of the population: it is estimated that $70 \%$ of the population does not engage in any routine physical activity. ${ }^{10}$

\section{LEADERSHIP AND GOVERNANCE/ HEALTH FINANCING SYSTEM}

The $\mathrm{MOH}$ was established under a royal decree in the 1950s. Later, in 1970, it incorporated a health initiative into the country's 5-year development plan, which has led to overall improvement of the health care system. This improvement is evidenced by several health care indicators and an increase in the number of health care workers and centres. ${ }^{2,11}$

The Saudi constitution requires the government to provide free health care and medications to all Saudi citizens. The $\mathrm{MOH}$ is responsible for providing health care at all levels to all Saudi citizens, including promotion of general health and prevention of diseases. It is also responsible for developing the health-related laws and regulations for both government (public) and private sectors. Moreover, the $\mathrm{MOH}$ is accountable for monitoring performance in health care institutions. ${ }^{12}$

In 2005, the government passed a law, under the Council of Cooperative Health Insurance Act, requiring all employers to medically insure their expatriate employees. Three years later, these provisions were expanded to cover Saudi nationals employed in the private sector, given that a sustainable, government-funded vision of health care had become unrealistic. ${ }^{9}$ Most private companies offer insurance plans covering medications for chronic disease states, yet excluding newly released or highly priced ones, such as cancer medications and newer hepatitis C medications. In 2015, the Council of Cooperative Health Insurance Act mandated that treatments up to US\$26 664 shall be covered. ${ }^{10}$ Roughly $69 \%$ of the population is covered by public insurance or services, whereas the remaining $31 \%$ have private insurance plans. According to 2010 data, the total share of pharmaceutical expenditure is $60 \%$ for the government sector and $40 \%$ for the private sector. ${ }^{13}$

As of $2013,59.6 \%$ of acute health care facilities were run by the $\mathrm{MOH}, 31.1 \%$ by the private sector, and $9.3 \%$ by other public sectors. ${ }^{6}$ As of 2014, there were 453 hospitals, of which 312 were governmental, and the total number of hospital beds in all sectors was 22.1 per 10000 population. ${ }^{5}$ The number of clinics run by the private sector exceeds the number of public primary health centres (2366 versus 2281). ${ }^{5}$ Funding is mainly provided through the government, followed by the private sector and public charities. ${ }^{2}$ Similar to many other countries, it is predicted that government will not be able to continue to meet the growing demand, and hence the private sector is expected to cover up to $39 \%$ of total health care expenditures by $2024 .{ }^{10}$

Saudi Arabia is trying to implement and utilize electronic medical records (EMRs). Recently, US $\$ 1.1$ billion has been allocated by the $\mathrm{MOH}$ for the development of electronic health services in its hospitals. Currently, most large hospitals use partial EMRs with some paper charts; only $15 \%$ use a complete EMR system. However, there is no nation-wide EMR system that can be used by health care professionals from different hospitals, clinics, or pharmacies to access patient care records. ${ }^{11}$

\section{HEALTH WORKFORCE}

The Kingdom of Saudi Arabia has a vast variety of health care workers, including physicians, nurses, pharmacists, psychologists, dentists, speech therapists, laboratory technologists, respiratory therapists, dieticians, physical therapists, and radiologists. One of the main challenges that the kingdom faces is a high turnover of health care providers, which could lead to instability in some health care institutions. This situation results from a shortage of local or Saudi national health care workers and a high dependence on expatriates recruited from other countries. To overcome this, the $\mathrm{MOH}$ is trying to increase the Saudi national health workforce by educating and training more Saudi health care staff in various fields, both locally and through government-funded scholarships for overseas study. ${ }^{2}$

The government is making progress: during the period from 2006 to 2013, there was growth in the numbers of physicians (by 27.6\%), dentists (by 68\%), nurses (by 31.1\%), pharmacists (by 19.5\%), and other allied health professionals (by 53\%). ${ }^{6}$ As of 2014, there were 22241 pharmacists in the country, of whom $20.6 \%$ were Saudi nationals. ${ }^{5}$ Complete nationalization or "Saudization" of the health care workforce will still take a while. According to a statement made by the Saudi Food and Drug Authority in 2012, it will take about 17 years to nationalize all pharmacy jobs in the Kingdom of Saudi Arabia at the current growth rate. The number of pharmacy students graduating each year was anticipated to reach 1000 in 2015 , with a predicted annual increase of $7 \%-10 \% .{ }^{11}$ As of 2014, there were 3.68 physicians for each pharmacist (Table 1). ${ }^{5,13}$

\section{Pharmacy Education}

There are currently 28 academic centres that grant pharmacy degrees, some offering a Bachelor in Pharmacy (BPharm) and others the Master-level (MSc) or Doctor of Pharmacy (PharmD) degrees. Most universities, however, are moving toward the PharmD curriculum, which hints that the BPharm degree will eventually be phased out. In some 
This single copy is for your personal, non-commercial use only.

For permission to reprint multiple copies or to order presentation-ready copies for distribution, contact CJHP at cjhpedit@cshp.ca

Table 1. Health Workforce Indicators (2014) ${ }^{5}$

\begin{tabular}{lrcc} 
Medical Indicator & \multicolumn{2}{c}{$\begin{array}{c}\text { Total Number in 2014 } \\
\text { (\% Who Are Saudis) }\end{array}$} & $\begin{array}{c}\text { Rate per } \mathbf{1 0 ~ 0 0 0} \\
\text { Population }\end{array}$ \\
\hline Physicians & 81532 & $(23.3)$ & 26.50 \\
Pharmacists & 22241 & $(20.6)$ & 7.23 \\
Nurses & 165324 & $(37.2)$ & 53.73 \\
Allied health professionals & 94960 & $(72.6)$ & 30.86 \\
Total no. of hospitals & 453 & & NA \\
Total no. of beds & 67997 & 22.1 \\
\hline
\end{tabular}

NA = not applicable.

programs, students start in the BPharm program with a possibility of progressing into the PharmD program if they meet specific criteria during their studies. The BPharm program is at least a 5 -year commitment, including a semester of internship or equivalent number of training hours in the summer, whereas the PharmD is a 6-year entry-level degree that includes a year of internship. The PharmD degree integrates more pharmacy practice and clinical pharmacy courses within the curriculum than the BPharm degree. It also eliminates some of the extra basic pharmaceutical sciences courses, such as pharmacognosy and medicinal chemistry. Furthermore, it encompasses more clinical clerkship rotations (between 45 and 50 weeks, depending on the program structure).

Some of the main challenges that face the implementation of clinical pharmacy education in Saudi Arabia are shortages of clinical faculty, qualified preceptors, and advanced practice sites for learning experiences. Some colleges of pharmacy are trying to address these issues by becoming affiliated with large hospitals that have clinical pharmacists available for rotation sites and preceptors, and inviting clinical pharmacists from the affiliated sites to become adjunct faculty. Another major issue is standardizing the curriculum of the PharmD program to meet the requirements of a pharmacy-specific accreditation body similar to the Accreditation Council for Pharmacy Education (ACPE) or the Council for Continuing Pharmaceutical Education. Therefore, some universities have started seeking ACPE international certification to address this issue. In 2011, King Saud University became the first institution outside the United States to receive ACPE certification. Currently, the country has 3 ACPE-certified colleges of pharmacy. However, all universities must be accredited by the country's National Commission for Academic Accreditation and Assessment.

\section{Residency Training}

The first pharmacy practice residency program was established in 1997 at a large tertiary care hospital in Riyadh, Saudi Arabia. Later, this program was adopted by the Saudi Commission for Health Specialties (SCFHS) as the standard, and it will serve as a stepping stone for the development of a national residency program in the country. Over the years, it has advanced to become a 24-month postgraduate program with structured training in clinical pharmacy under the auspices of the SCFHS, which is also responsible for accrediting residency practice sites in all health care disciplines, including pharmacy.

The first 12 months of the residency focus on hospital inpatient and ambulatory care pharmacy practice, as well as drug information and administration, with the second year focusing more on a wide variety of clinical rotations in different specialties. ${ }^{14}$ The purpose of the postgraduate year 1 (PGY1) residency is to prepare residents to be independent pharmacy practitioners, with a higher level of skills and knowledge, so that they can assume advanced practice roles. ${ }^{15}$ There are currently about 60 PGY1 residents, and every year nearly 30 residents are accepted into these programs. The 2-year residency program certificate is equivalent to a professional master's degree from the Ministry of Civil Services and provides the opportunity to be promoted to a higher job classification. In 2011, the first pharmacy practice residency program also became the first program outside of the United States to be accredited by the American Society of Health-System Pharmacists (ASHP).${ }^{14}$ There are currently 3 ASHP-accredited PGY1 programs across the country, and only 1 ASHP-accredited PGY2 program (the Solid Organ Transplant Pharmacy Residency at King Faisal Specialty Hospital and Research Center).

There are also several PGY2 residency programs solely under the auspices of the SCFHS in the following fields: nutrition, cardiology, critical care, internal medicine, nephrology, infectious disease, pediatrics, solid organ transplant, and hematology/oncology. PGY2 residencies build upon the competencies introduced during the PGY1 program, aiding the resident to become a clinical pharmacy specialist in an advanced specialty of pharmacy practice. ${ }^{16}$ Having both PGY1 and PGY2 residencies is equivalent to a professional $\mathrm{PhD}$ and qualifies the graduate to become a consultant pharmacist after 3 years of experience.

\section{Licensing and Registration}

The SCFHS is the licensing and registration body for all health care providers, including pharmacists, nurses, and physicians. All students graduating from pharmacy, nursing, and medicine must undergo a licensure exam. Graduates from 
foreign pharmacy schools are required to be licensed by SCFHS as well. Their certificates/degrees must be verified through a data flow system, and they must sit for a licensing examination.

The licensure classification of pharmacists by the SCFHS is important for Saudi nationals because it determines their salary on a "unified pay scale" that was recently implemented across all public health care sectors. The aims of this unified pay scale are to improve retention of health care workers in public hospitals and to reduce attrition rates. The SCFHS classifies each pharmacist into 1 of the following 3 categories: pharmacist, pharmacist I, or consultant pharmacist. To be classified as a pharmacist, the applicant must have graduated from a 5-year (minimum) BPharm program and must pass the licensing exam. Hence, applicants from overseas with a 4-year BPharm will not be classified as pharmacists by the SCFHS. To be classified as a pharmacist I, the applicant must have a Master's degree (MPharm/MSc) or a PharmD plus experience or a PGY1 residency. To be classified as a consultant pharmacist, the applicant must have a PharmD or BPharm degree with completion of PGY1 and PGY2 residencies or must have a PhD degree in addition to a minimum of 1 year of experience. To maintain licensure, a pharmacist or pharmacist I needs to complete 20 hours of continuing education, whereas a consultant pharmacist will have to complete 25 hours annually.

Applicants for licensure as a pharmacy technician must have a diploma from a 2.5-year program at an academic institution and must pass a licensing exam.

\section{Pharmacy Professional Societies}

In 1988, when the Saudi Pharmaceutical Society was founded, it became the only society representing pharmacy in the Kingdom of Saudi Arabia. It currently has more than 4000 members and provides continuing education that is recognized by the ACPE. Its mission is to develop and implement continuing education for pharmacists and to improve awareness of the pharmacist's role in relation to other health care professions and within the community in general. ${ }^{17}$

\section{Medication Regulation and Prescriptive Authority}

The Saudi Food and Drug Authority regulates all matters related to pharmaceutical products, including prescription medications, behind-the-counter products, over-the-counter products, herbal products, and food supplements. However, it does not regulate medical or pharmacy practice. Nonetheless, the Saudi Food and Drug Authority can place prescribing restrictions on the basis of specialty and licence classification of physicians. For example, the prescribing of antineoplastic agents that have no other indication outside the field of oncology is restricted to the rank of specialist physician and above. Health care institutions may grant prescriptive authority to nonphysician health care providers and may also place prescribing restrictions on both physicians and other health care providers such as nurse practitioners or clinical pharmacists within their institution. Nonphysicians with prescriptive authority are only allowed to prescribe medications within their scope of practice and under collaborative practice agreements with physicians. In contrast, the Controlled Drug Act restricts prescriptive authority for controlled substances to physicians and dentists in both community and hospital settings.

\section{AREAS OF PRACTICE}

Pharmacists not only practice in hospital and community pharmacies but also are involved in nontraditional settings, such as regulatory activities (working within the Saudi Food and Drug Authority for drug evaluation, Good Manufacturing Practice [GMP] inspection, customs release, and pharmacovigilance), the pharmaceutical industry (sales and marketing, scientific office, manufacturing site, or licensing and regulation department), and teaching and academic institutions. The majority of pharmacy technicians practise in hospital settings, where the need for their skills is greater than in other settings.

\section{Community Pharmacy}

In the community setting, pharmacists take on the traditional roles of dispensing and counselling. There are 3 classes of medications: over-the-counter (those that can be accessed without a prescription, which are within patients' reach), behind-the-counter (those dispensed by a pharmacist without a prescription, which are not within patients' reach), and prescription (those that require a prescription). It is against the law for pharmacists to diagnose a patient's disease or to dispense medications without prescription. Unfortunately, many pharmacists continue to dispense medications for chronic diseases, oral contraceptives, and antibiotics without prescriptions. The $\mathrm{MOH}$, the sole regulating body for community pharmacies, attributes the lack of enforcement to an insufficient number of inspectors. ${ }^{11}$ This situation is concerning, given local research showing that community pharmacists in the Kingdom of Saudi Arabia lack adequate training and clinical skills to diagnose and/or prescribe. ${ }^{11,18}$ The only situation where pharmacists strictly adhere to the law relates to controlled/narcotic substances, because of serious legal consequences.

Most community pharmacists are not Saudi nationals and have received their degrees mainly from other countries in the Middle East and the Far East. ${ }^{6}$ Most of them have BPharm degrees, and their training does not include much or any practice-based learning; hence, these programs may not be equivalent to the local pharmacy curricula. Saudi pharmacists tend to avoid the community setting because the pay is not as good as it is in other settings and the job satisfaction is less. 
Furthermore, pharmacies do not keep any patient records and information is not relayed back to the primary care provider because of a lack of electronic documentation.

The law about who is allowed to own a pharmacy has changed several times over the years. Currently, only Saudi national pharmacists can own and manage community pharmacies. Nonpharmacists are allowed to partner with Saudi pharmacists in the establishment and ownership of a community pharmacy; however, the manager must be a licensed pharmacist.

\section{Institutional Pharmacy}

Hospital pharmacy practice in Saudi Arabia is considered one of the best and most advanced practices in the region. Most Saudi pharmacists end up practising in hospital settings, rather than retail pharmacies, because of higher wages and better job satisfaction. Residency training is not a requirement to practise as a staff pharmacist. Candidates are hired on the basis of experience. However, most specialized clinical positions require some form of higher postgraduate training. The role of hospital staff pharmacists includes but is not limited to medication verification and dispensing, management of medication storage and supplies, provision of drug information to other health care providers, and training of residents and students. Some participate in other specialized areas, such as sterile preparation of medications or chemotherapy and parenteral nutrition. In addition, pharmacists are involved in the identification and reporting of adverse drug events (ADEs) or pharmacovigilance. Most hospitals have an ADE reporting program, a medication error reporting program, and a multidisciplinary medication safety committee. The committee's tasks are to review and analyze reported $\mathrm{ADEs}$ and medication errors, and then create policies or system modifications to avoid future errors. As the significance of quality improvement has grown, hospitals have developed quality improvement positions in the pharmacy department. These hospitals recognize the importance of improving the quality of health care, and many are accredited by the Joint Commission International. Outcomes such as patient satisfaction, number of prescriptions filled, patient wait time, number of dispensing errors, and many other key performance indicators are measured, and services are adjusted on the basis of these outcomes. There is still a gap between pharmacy practice in large tertiary care hospitals and pharmacy practice in smaller MOH hospitals, where many of the abovementioned activities do not take place because of limited resources or staff qualifications.

Pharmacists have also played a role in public health awareness days, which can take place in patient areas in hospitals or in locations in the community, such as shopping malls. Some pharmacists are involved in making recommendations about health care strategies at their institutions and even at the national level. Two pharmacists currently serve on the National Vaccination Technical Advisory Group alongside other health care providers. However, the actual administration of vaccines is still carried out by nurses. 5

Most hospitals have drug information centres, but few have investigational drug services run by pharmacists. More recently, pharmacists have also been encouraged to conduct medication therapy management, whether through discharge counselling or pharmacist-run clinics. Most teaching hospitals and tertiary care hospitals have established policies, procedures, and pathways in place for pharmacists to follow. Moreover, many hospitals provide certain pharmacy services with 24-h coverage.

\section{Hospital Drug Distribution}

Most hospitals, especially public hospitals, have a closed formulary system and use a tendering approach for purchasing medications (i.e., a unified bidding and purchasing system for all government sectors, for cost minimization and containment). ${ }^{19}$ Nonformulary items can still be procured, if deemed necessary, on an individual patient basis.

The drug distribution systems in hospitals vary across the kingdom. Some are completely decentralized with satellite pharmacies, others are completely centralized with cart-fills, and some are hybrids, with both a central pharmacy and satellite pharmacies. ${ }^{20} \mathrm{~A}$ recent report showed that $74 \%$ of hospitals have a completely centralized drug distribution system, with larger hospitals tending to have a decentralized system or a hybrid system that involves automated dispensing machines (ADMs). This pattern is comparable to the United States, where about $75 \%$ of smaller hospitals also have a centralized system. Some Saudi hospitals are advanced and have sophisticated robotics in both inpatient and outpatient pharmacies. ${ }^{20}$ It is estimated that $21 \%$ of hospitals use ADMs, $10.3 \%$ have $\mathrm{ADMs}$ that are connected to a computer system ("profiled ADMs"), and $17.1 \%$ have ADMs in a decentralized setting. ${ }^{20}$ About $20.6 \%$ of the hospitals also use some form of bar coding technology, with or without a robot for dose verification..$^{20}$ Among hospitals with dispensing on patient care units, most (65.4\%) have the pharmacy technicians prepare the dose, which is then verified by a pharmacist. However, some hospitals use the "tech-check-tech" method (10.3\%), whereas others have a pharmacist prepare the dose without any other verification (24.1\%). In contrast, for medications supplied to high-risk patients, such as pediatric patients, $68 \%$ of hospitals require a dual-check method. For high-risk medications like chemotherapy, $60 \%$ of hospitals require verification by 2 different pharmacists. ${ }^{20}$

The majority of hospitals $(60.7 \%)$ have a sterile preparation area in the pharmacy department. Conversely, $21.7 \%$ of IV admixtures and solution doses from vials or ampules are 
prepared by the nursing staff. About half of all hospitals (46.3\%), predominantly the larger ones, dispense total parenteral nutrition products, with only $12 \%$ using smart pump infusions. ${ }^{20}$

\section{Clinical Pharmacy}

Clinical pharmacy is relatively well developed in Saudi Arabia, especially in tertiary care hospitals and, to a lesser extent, $\mathrm{MOH}$ hospitals. The concept was first introduced in the 1970s, when clinical pharmacists from the United States developed pharmacokinetic, parenteral nutrition, and drug information services at the King Faisal Specialist Hospital and Research Centre in Riyadh. ${ }^{11}$ Hence, many institutions try to emulate the standards of clinical pharmacy found in the United States, and some hospitals have used and directly adopted those standards.

Clinical pharmacy has further evolved and expanded with the return of Saudi national pharmacists after completion of their PharmD and residency training, mainly in the United States through government-funded scholarships. Many trainees are still overseas and are expected to return after completion of their programs in the near future. With the number of returning clinical pharmacists and the introduction of SCFHS specialized residency training in the country, the numbers of clinical pharmacists are expected to further increase. According to the Board of Pharmacy Specialties, as of early 2016 Saudi Arabia had 267 board-certified pharmacists, making it the country with the fourth-highest number of board-certified pharmacists in the world. ${ }^{21}$

Clinical pharmacists have established their presence and impact in many areas, including adult and pediatric oncology and hematology, solid organ transplant, ambulatory care, general surgery, adult surgical and medical intensive care, neonatal and pediatric intensive care, nephrology, internal medicine, anticoagulation, discharge, cardiology, pain management, drug information, infectious diseases, pediatrics, parenteral nutrition, and investigational drug services. Many have the traditional roles of rounding with the health care team on their service; others are also part of pharmacist-run clinics. Available pharmacist-run clinics include anticoagulation, cardiology, HIV, oncology, pain, solid organ transplant, and ambulatory care. The pharmacists running these clinics are usually consultant clinical pharmacists who have completed their postgraduate training in developed countries. Some have created collaborative practice agreements with physicians in the department of which the clinic is a part. Such agreements give the pharmacists prescriptive authority, meaning that they can order laboratory tests and medications as authorized in the terms of the agreement.

Many hospitals have 24-h clinical coverage through an on-call clinical pharmacist, for pressing issues that need to be addressed after hours. Besides their clinical duties, many clinical pharmacists also serve as preceptors for students and residents and teach at affiliated universities. Furthermore, some have immersed themselves in research and publishing, which are highly encouraged at certain institutions. To capture some of the impact of clinical pharmacists, some hospitals have utilized specific key performance indicators to measure their contribution to patient care. Pharmacists are required to record or keep track of their interventions and/or recommendations to aid in assessment of these indicators. These assessments are used for evaluation purposes and to justify the opening of new clinical pharmacist positions.

\section{FUTURE DIRECTION AND CHALLENGES}

Despite tremendous progress, pharmacy, like any other profession, still has challenges and hurdles that need to be addressed. As previously mentioned, the number of welleducated and trained Saudi national health care professionals, including pharmacists, is low. It is estimated that complete nationalization of the pharmacy profession will not take place until 2029, if it ever occurs. ${ }^{11}$ Recruitment of well-trained pharmacists from overseas has been and continues to be challenging. Moreover, the pharmacists currently working in the kingdom are not equally distributed across specialties, practice sites, or hospitals. For example, there are more hospital pharmacists in the public sector than the private sector. Furthermore, residency-trained clinical pharmacists are spread even thinner in the academic setting, despite the fact that their presence in this setting is imperative to educate and develop a cadre of well-trained Saudi national pharmacists.

One of the other challenges is the registration, classification, and pay scale for pharmacists and other health care workers. The way in which a pharmacist is classified determines his or her salary on the basis of a unified pay scale. There has been enormous criticism of this payment system, on the basis that it does not take into account the differences between large and small hospitals, where workload and responsibilities differ substantially. It would be beneficial to create clear accreditation, registration, and classification standards. It is predicted that the classification system will be revisited in the near future, with a greater emphasis placed on training. ${ }^{11}$

In addition, there is a gap in pharmacy practice between the hospital setting and retail pharmacies, which requires a further look into malpractice that is taking place in community settings and enforcement of existing laws and regulations. Finally, the discrepancy in the level of pharmacy practice between the public and private sectors and between large tertiary care hospitals and smaller ones, especially those under the $\mathrm{MOH}$, is huge.

\section{CONCLUSION}

The pharmacy profession is continually evolving in Saudi Arabia. Pharmacists have opportunities to practice in a variety 
of settings. However, most Saudi national pharmacists end up practising in hospital settings, which leaves the community pharmacy setting underdeveloped. Some pharmacists have an advanced-level practice in hospitals, with collaborative practice agreements and prescriptive authority within their institutions. Community pharmacy settings need more stringent regulations and introduction of more pharmacists with more practice-based training. The number of pharmacists in the workforce is still an issue, but this concern is being addressed in the government's 5-year developmental plan and is expected to be at least partially resolved by $2029 .{ }^{11}$

\section{References}

1. The annual report 2015. Riyadh (Saudi Arabia): Central Department of Statistics and Information; 2015 [cited 2015 Nov 14]. Available from: www.cdsi.gov.sa/en

2. Country cooperation strategy for WHO and Saudi Arabia 2012-2016. WHO-EM/PME/003D. Cairo (Egypt): World Health Organization, Regional Office for the Eastern Mediterranean; 2015 [cited 2015 Nov 14]. Available from: www.who.int/countryfocus/cooperation_strategy/ ccs_sau_en.pdf?ua $=1$

3. Saudi Arabia: human development indicators. United Nations Development Programme; 2015 [cited 2016 Mar 22]. Available from: http:// hdr.undp.org/en/countries/profiles/SAU

4. Musgrove P, Creese A, Preker A, Baeza C, Anell A, Prentice T. The world health report 2000. Health systems: improving performance. Geneva (Switzerland): World Health Organization; 2000 [cited 2016 May 31]. Available from: www.who.int/whr/2000/en/whr00_en.pdf

5. Statistical year book Kingdom of Saudi Arabia 2014 G / 1435 H. Riyadh (Saudi Arabia): Ministry of Health; 2014 [cited 2015 Nov 14]. Available from: www.moh.gov.sa/en/Ministry/Statistics/book/Documents/StatisticalBook- for-the-Year-1435.pdf

6. Health statistics annual book Kingdom of Saudi Arabia 2013 G / 1434 H. Riyadh (Saudi Arabia): Ministry of Health, General Directorate of Statistics \& Information; 2013 [cited 2015 Nov 14]. Available from: www.moh.gov.sa/en/Ministry/Statistics/book/Documents/StatisticsBook-1434.pdf

7. Saudi Arabia: WHO statistical profile. Geneva (Switzerland): World Health Organization; 2015 [cited 2015 Nov 14]. Available from: www.who.int/gho/countries/sau.pdf?ua=1

8. Transition to knowledge society in Saudi Arabia. King Abdul Aziz City for Science and Technology, Ministry of Economy \& Planning, Madar Research \& Development; (C) 2014-2015 [cited 2015 Nov 14]. Available from: http://publications.kacst.edu.sa/SystemFiles/Books_Pdf/PDF_ 635518951661650873.pdf

9. Almalki M, Fitzgerald G, Clark M. Health care system in Saudi Arabia: an overview. East Mediterr Health J. 2011;17(10):784-93.

10. Saudi Arabia pharmaceuticals and healthcare report. London (UK): BMI Research; 2015 [cited 2015 Nov 14]. Available from: http://store. bmiresearch.com/saudi-arabia-pharmaceuticals-healthcare-report.html
11. Fathelrahman A, Ibrahim M, Wertheimer A. Pharmacy practice in Saudi Arabia. In: Pharmacy practice in developing countries: achievements and challenges. New York (NY): Academic Press; 2016. pp. 172-95.

12. Ministry of Health portal: about the Ministry [homepage]. Riyadh (Saudi Arabia): Ministry of Health; 2015 [cited 2015 Nov 14]. Available from: www.moh.gov.sa/en/Ministry/About/Pages/Mission.aspx

13. Saudi Arabia: pharmaceutical country profile. Riyadh (Saudi Arabia): Saudi Food and Drug Authority; 2012 [cited 2015 Nov 14]. Available from: www.who.int/medicines/areas/coordination/Saudi_ArabiaPSCP Narrative2012-04-18_Final.pdf

14. Al-Qadheeb N, Alissa D, Al-Jedai A, Ajlan A, Al-Jazairi A. The first international residency program accredited by the American Society of Health-System Pharmacists. Am J Pharm Educ. 2012;76(10):190.

15. ASHP accreditation standard for Postgraduate Year One (PGY1) pharmacy residency programs. Bethesda (MD): American Society of Health-System Pharmacists; 2014 [cited 2015 Nov 14]. Available from: www.ashp.org/DocLibrary/Accreditation/Newly-approved-PGY1Standard-September-2014.pdf

16. Online residency directory. Bethesda (MD): American Society of HealthSystem Pharmacists; 2015 [cited 2015 Nov 14]. Available from: www.ashp.org/DocLibrary/Accreditation/ASD-PGY2-Standard.aspx

17. Saudi Pharmaceutical Society [homepage]. The Society; (C) 2009-2012 [cited 2015 Nov 14]. Available from: www.pharma.sa/public/english/ Index

18. Al-Arifi M. The managerial role of pharmacist at community pharmacy setting in Saudi Arabia. Pharmacol Pharm. 2013;4(1):63-70.

19. Al-Jazairi A, Bhareth S, Eqtefan I, Al-Suwayeh S. Brand and generic medications: Are they interchangeable? Ann Saudi Med. 2008;28(1):33.

20. Alsultan M, Khurshid F, Mayet A, Al-jedai AH. Hospital pharmacy practice in Saudi Arabia: dispensing and administration in the Riyadh region. Saudi Pharm J. 2012;20(4):307-15.

21. Board of Pharmacy Specialties [homepage]. Washington (DC): The Board; 2015 [cited 2016 May 30]. Available from: http://bpsweb.org/

Ahmed Al-jedai, PharmD, MBA, BCPS, FCCP, is with the Pharmaceutical Care Division, King Faisal Specialist Hospital and Research Centre, and College of Medicine, Alfaisal University, Riyadh, Saudi Arabia.

Shrouq Qaisi, PharmD, is with the Pharmaceutical Care Division, King Faisal Specialist Hospital and Research Centre, Riyadh, Saudi Arabia.

Ahmed Al-meman, MSc, PhD, is with the College of Medicine, Qassim University, Onaiza, Alqassim, Saudi Arabia.

Competing interests: None declared.

Address correspondence to:

Dr Ahmed Al-jedai

Pharmaceutical Care Division

King Faisal Specialist Hospital and Research Centre

MBC-11

PO Box 3354

Riyadh 11211 Saudi Arabia

e-mail: jedai@kfshrc.edu.sa 